\title{
Lipomembranous changes (membrano-cystic lesions) in the extremities of a patient with systemic sclerosis
}

\section{Natsuko Matsumura, Toshiyuki Yamamoto}

\author{
Department of Dermatology, Fukushima Medical University, Fukushima, Japan
}

Corresponding author: Prof. Toshiyuki Yamamoto, E-mail: toyamade@fmu.ac.jp

Sir,

We herein describe a case of nodular cystic fat necrosis (NCFN) that occurred in the forearm of a patient with systemic sclerosis (SSc). Of interest, lipomembranous changes were also observed in the biopsy specimens taken from the forearm and the finger.

An 83-year-old woman was referred to our department on suspicion of SSc, during admission in the respiratory medicine department. She had had surgery one year previously for breast cancer. Physical examination showed mildly swollen fingers with nail fold bleeding (Fig. la). Further examination revealed a solitary bony-hard, mobile subcutaneous nodule, sized $10-\mathrm{mm}$ in diameter located on the edematous forearm (Fig. 1b). A biopsy specimen from the finger showed

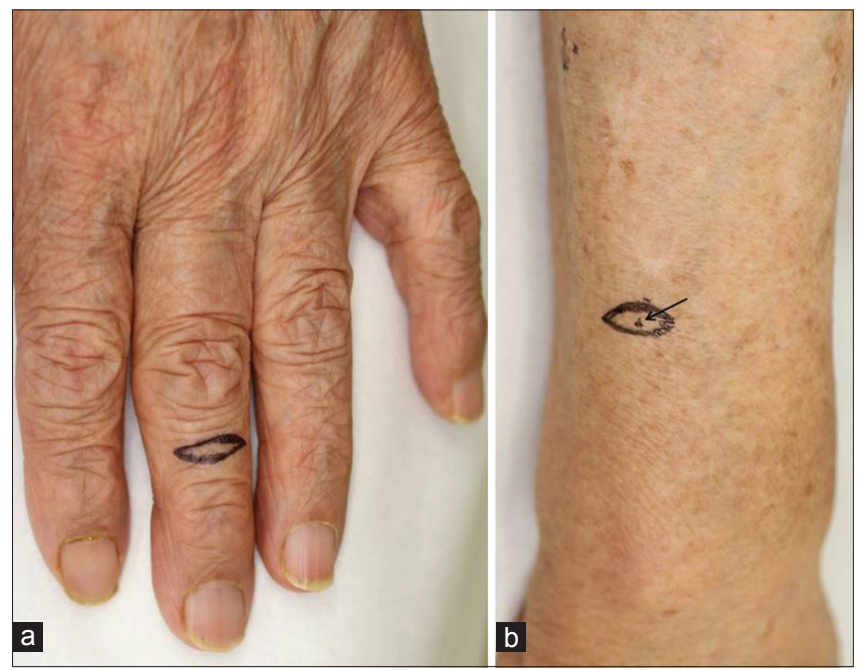

Figure 1: Mildly swollen fingers (a). Subcutaneous nodule on the forearm (arrow) (b). thickened collagen bundles in the dermis (Fig. 2a), and lipomembranous changes in the subcutaneous tissues (Fig. 2b). Another biopsy from the forearm showed edematous dermis with slightly thickened collagen bundles in the lower dermis, with lipomembranous changes in the subcutis (Figs. $2 \mathrm{c}$ and $2 \mathrm{~d}$ ). The nodule of the forearm was simultaneously removed, which histologically revealed a well-circumscribed tumor composed of degenerated fat cells with lipomembranous lesions surrounded by a thin fibrous capsule (Figs. 2e and 2f). Laboratory data showed normal liver and renal function and an increased level of KL-6 (3581 U/ml; normal <500). Antinuclear

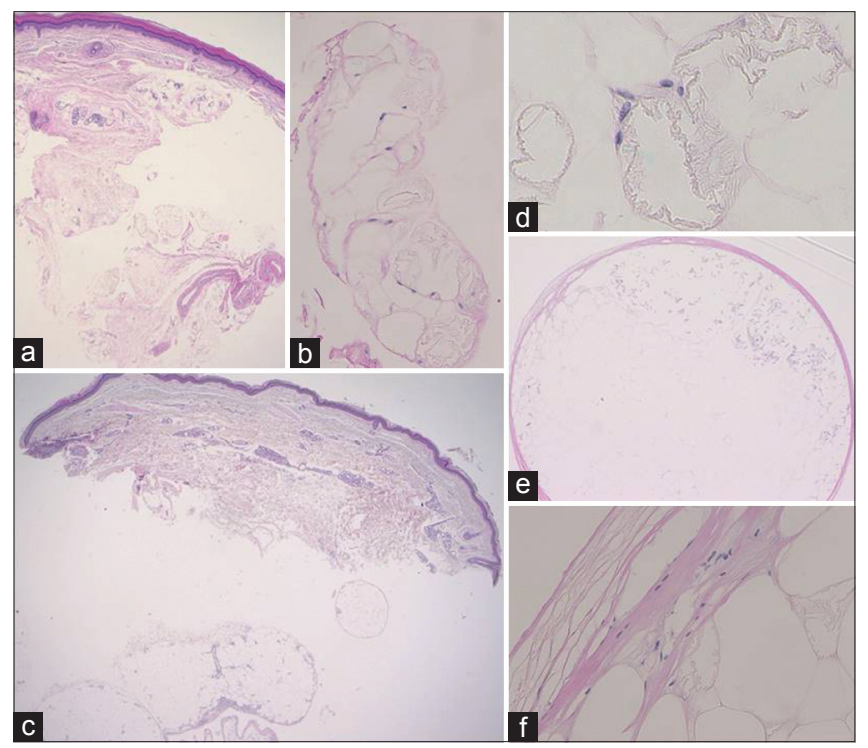

Figure 2: Histology of the biopsy specimen from the finger (a), with lipomembranous changes in the subcutaneous tissues (b). Another biopsy from the forearm showed slightly thickened collagen bundles in the lower dermis (c), with lipomembranous changes in the subcutis (d). A nodule on the forearm was a well-circumscribed tumor (e), showing lipomembranous changes within the nodule (f).

How to cite this article: Matsumura N, Yamamoto T. Lipomembranous changes (membrano-cystic lesions) in the extremities of a patient with systemic sclerosis. 2018;9(1):105-106.

Submission: 05.06.2017; Acceptance: 02.07.2017

DOI: 10.7241 /ourd.20181.35 
antibodies (1:80), and anti-centromere antibodies $(17 \mathrm{U} / \mathrm{ml}$; normal $<10)$ were detected in the serum, whereas antibodies against Scl-70, UlRNP, SS-A, SS-B, DNA, ds-DNA, Sm, PR3-ANCA, and MPO-ANCA were all negative or within normal limits. Lung computed tomography showed interstitial fibrosis. Also, she had reflux esophagitis.

NCFN most commonly occurs on the lower extremities. Histology shows multiple, non-viable adipocytes surrounded by condensed fibrous tissues, along with lipomembranous changes $[1,2]$. Lipomembranous changes are sometimes associated with vascular diseases or connective tissue diseases due to the interruption of the blood supply in the subcutaneous tissues [3]. Snow et al. reported three cases of morphea in their series, which presented with lipomembranous changes on the morpheaform plaques of the back, legs, and calf [4]. To date, only a few cases of SSc similar to ours were reported $[5,6]$. In one case, mobile nodules appeared on the forearm, and histological examination revealed NCFN [5]. Furthermore, lipomembranous changes were observed in the biopsy specimens taken from the forearm. In another case, a biopsy from the abdominal hard hyperchromic plaque with coalescent and painful nodules revealed lipomembranous panniculitis [6]. In the present case, lipomembranous changes were observed in the specimens from both forearm and finger unrelated with the lesion of NCFN. Therefore, it is suggested that lipomembranous changes are associated with SSc-related conditions. SSc skin shows pronounced vascular changes in the subcutis, such as a paucity of blood vessels, thickening and hyalinization of the vessel walls, and narrowing of the lumen. Such changes may be predisposed for the induction of lipomembranous changes due to ischemia. However, reports of similar cases are few, and therefore, other factors may be associated with the induction of lipomembranous changes. Alternatively, those features involved in the subcutis may have been underestimated in SSc.

\section{Consent}

The examination of the patient was conducted according to the Declaration of Helsinki Principles.

Written informed consent was obtained from the patient for publication of this article.

\section{REFERENCES}

1 Ahn SK, Lee BJ, Lee SH, Lee WS. Nodular cystic fat necrosis in a patient with erythema nodosum. Clin Exp Dermatol. 1995;20:263-

2 Pujol RM, Wang CY, Gibson LE, Su WP. Lipomembranous changes in nodular-cystic fat necrosis. J Cutan Pathol. 1995;22:551-5.

3 Snow JL, Su WP. Lipomembranous (membranocystic) fat necrosis: clinicopathologic correlation of 38 cases. Am J Dermatopathol. 1996;18:151-5.

4 Snow JL, Su WP, Gibson LE. Lipomembranous (membranocystic) changes associated with morphea: a clinicopathologic review of three cases. J Am Acad Dermatol. 1994;31:246-50.

5 Toritsugi M, Yamamoto T, Nishioka K. Nodular cystic fat necrosis with systemic sclerosis. Eur J Dermatol. 2004;14:353-5.

6 Almeida MS, Lima SC, Carvalho LL, Almeida JV, Santos LG, Rolim JR, et al. Panniculitis: an unusual cutaneous manifestation of systemic sclerosis. J Cutan Pathol. 2010;37:1170-3.

Copyright by Natsuko Matsumura, et al. This is an open access article distributed under the terms of the Creative Commons Attribution License, which permits unrestricted use, distribution, and reproduction in any medium, provided the original author and source are credited.

Source of Support: Nil, Conflict of Interest: None declared. 